\title{
UV radiation theory and the Lynn (2010) Italian debate
}

Federico R. León

Universidad San Ignacio de Loyola

Av. La Fontana 550, Lima 12, Peru Corresponding author: e-mail federicorleone@gmail.com

Mayra Antonelli-Ponti

Psychobiology Unit, University of Sao Paulo at Riberao Preto, Brazil Email: antonellimay@gmail.com

Author Note

The authors have a debt of gratitude with Vittorio Daniele and Antonio di Ruggiero, who facilitated access to secondary data and provided valuable comments, and with Michael Woodley of Menie and Gerhard Meisenberg, who provided valuable comments.

Correspondence concerning this article should be addressed to Federico R. León, Universidad San Ignacio de Loyola, Av. La Fontana 550, Lima 12, Peru. E-mail: fleon@usil.edu.pe.

Lynn's (2010) attribution of decreasing north-to-south PISA scores and GDP in Italy to inherited intelligence caused debate, but cognitive-capitalism's tenet that regional/national intelligence, inherited or not, determines provincial/country wealth remains unchallenged. We introduce a new theory into the debate and test a UV radiation $\rightarrow$ intelligence $\rightarrow$ socioeconomic latent variable (SELV) model visà-vis a radiation $\rightarrow$ SELV $\rightarrow$ intelligence one. Only the latter is found well-adjusted in Italy, more so among adolescents than children. Since hair and eye color vary with latitude in Italy and UV radiation could be a proxy for ancestry, the models are retested among White students in the USA. Similar results observed suggest that, in both countries, increased UV radiation impairs socio-economic development, perhaps by reducing industriousness through oxidative stress. The ensuing lessdeveloped social environments exert negative influences on individuals' cognition. Yet, ancestry appears to add latitudinal socioeconomic variance in Italy. A third study in Brazil, in turn, shows that cognitive effects of UV radiation through SELV are clearly distinguishable from the cognitive effects of race. The results suggest that the postulate that intelligence causes wealth needs revision.

Key Words: UV radiation; Intelligence; Socioeconomic latent variable; Italy; USA; Brazil 
According to Lynn (2010), inherited intelligence explains the decreasing wealth seen from Italy's north to south. He attributed PISA scores' dependence on latitude to genetic material from middleEuropeans (higher IQs) versus Greeks, Near Easterners, and North Africans (lower IQs) prevailing, respectively, among northern and southern Italians. In a different debate, cognitive-capitalism researchers propose that intelligence, whether inherited or not, determines wealth (Rindermann, Kodila-Tedika \& Christainsen, 2015 versus León, 2018).

Three major issues were addressed in the Italian debate. (1) The sample size of the PISA methodology and its targeting 15 year-old students were criticized. INVALSI, an Italian institution, uses larger samples which additionally include children. The northern intellectual advantage is less dramatic in INVALSI scores than in PISA scores (Cornoldi et al., 2010; Cornoldi, Giofré \& Martini, 2013) or is not seen at all in the first years of school (Daniele \& Malanima, 2011; Robinson, Saggino \& Tommasi, 2011). On the other hand, significant latitude-IQ-GDP correlations have emerged in the Raven standardization in Italy (Cornoldi et al., 2010) - objected by D'Amico et al. (2012) - and in other tests (e.g., Piffer \& Lynn, 2014). (2) A lack of evidence of heritability was noted, but Templer (2012) showed that higher IQ in Italy is associated with biological variables more characteristic of Central European than Mediterranean populations (e.g., cephalic index, eye color). Lynn (2012a) reported Italian correlations between latitude, percentage of blond hair, and frequency of the xR1a allele (a marker for European Mesolithic populations) and E1b1b allele -(a marker for North African ancestry), as well as between the genetic markers and PISA scores. On the other hand, the northsouth differences in wealth would only have emerged in the process of Italian industrialization (Daniele \& Malanima, 2014), and a trend toward north-south convergence of PISA scores over the years has been reported (Cornoldi et al., 2013; Daniele, 2015). (3) Causality was debated, too; government investment in school infrastructure and the quality of education, greater in northern than southern Italy, may have enhanced IQ differentially (Cornoldi et al., 2010; D'Amico et al., 20102010 or 2012?; Daniele, 2015). Furthermore, Beraldo (2010) showed that IQ predicts per capita GDP in bivariate relationships but not when employment or education enter as predictors. The Lynn debate acquires new meaning in the perspective of UV radiation theory of intelligence (León \& Burga-León, 2014, 2015), developed to explain the latitude-IQ relationship.

\section{UV radiation theory}

There was a time when IQ tests were regarded as biased against non-Western populations (Steinberg, Dornbusch, Brown, Stevenson, Chen, Stigler, \& Hsu, 2004). However, it is known now that the mean IQ score of a country captures the same cognitive abilities targeted by PISA and other standardized student assessments and that populations of Northeast Asia score higher than Europeans on both types of measures; the common factor is called complex cognitive ability or CCA (Rindermann, 2007a). Whether measured by IQ tests, standardized student assessments, or a combination of them, CCA increases with distance from the equator between nations (Lynn \& Vanhanen, 2012) and within such diverse countries as Italy, Japan, Peru, Russia, Spain, Sudan, and the USA, although not in India and Turkey (León \& Hassall, 2017). Parallel improvements are seen in health, wealth, and education, whereas total fertility rate (TFR) presents the opposite relationship. Identification of the variables at the roots of these phenomena could improve understanding of country development processes.

Recent theorization suggests that UV radiation (UVR) is the ultimate cause. As UVR decays with distance from the equator, production of vitamin $D$ by the skin and retina becomes weaker (Jablonski, 2004); vitamin D is a hormone that activates genes which sustain the levels of estrogen in females and testosterone in males (Jones, Strungnell, \& DeLuca, 1998). Their probable weakening with proximity to the poles due to scarcity of UV photons might help to 
understand the lower TFRs seen at higher absolute latitudes (Bongaarts, 2008). TFR's rough equivalence to family size is suggestive considering that smaller families come with higher CCAs, apparently because they provide children with better social environments (Kristensen \& Bjerkedal, 2007). Thus, a UVR $\rightarrow$ TFR $\rightarrow$ CCA connection would explain the absolute latitudeIQ correlation (León \& Burga León, 2014). UVR drives also oxidative stress (Jablonski, 2004), a condition involving generation of free radicals which causes cellular or tissue damage; systemic oxidative stress is related to cognitive impairment (Cervellati, Romani, Seripa, Cremonini, Bosi, Magon, S., ... \& Zuliani, 2014). Suggestively, oxidative stress causes fatigue (Fukuda, Nojima, Motoki, Yamaguti, Nakatomi, Okawa, ... \& Kuratsune, 2016), which probably reduces industriousness (DeYoung, Quilty, \& Peterson, 2007), thus impairing children's school progress. The UVR $\rightarrow$ health + education $\rightarrow$ CCA and wealth chain of effects that has been postulated (León, 2018) is consistent with evidence that free radicals are implicated in the pathology of important human diseases (Aruoma, 1998) and high rate of disease associates with diminished CCA (Daniele \& Ostuni, 2013). The negative disease-CCA linkage is attributed to competition for energy between the immunological system and the growth needs of the child's brain (Eppig, Fincher, \&Thornhill, 2011). UVR theory has been upheld in a study of 124 countries (Azam, 2017). Hence, contemporary UVR rather than inherited intelligence could explain Lynn's (2010) findings in Italy.

\section{Study 1}

Study 1 was designed to test hypotheses bearing on Lynn's debate, in conjunction with cognitive capitalism's tenet that CCA causes wealth.

Hypothesis 1: UVR impairs CCA which in turn affects wealth.

Hypothesis 2: UVR impairs wealth which in turn affects CCA.

\section{Methods}

\section{Subjects}

Whereas Lynn (2010) worked with 12 Italian regions, this study includes the 19 Italian regions and two autonomous provinces (Trento and Bolzano). Since the units of observation/analysis are aggregates, the reliability of the data is considerably greater and their standard errors are smaller than those of individual observations. Therefore, sample size should not be judged with the standards which apply to individual observations.

\section{Cognitive scores}

Math and reading scores obtained by15-year-old Italian students in the 2012 PISA round (INVALSI, 2013) were analyzed. Science scores were ignored considering their redundancy with more researched verbal and math scores. INVALSI (2016) offered its own measurements of math and Italian for the same regions and provinces encompassing students in $2^{\text {nd }}$ and $5^{\text {th }}$ grades of primary school and students in secondary school (lower secondary, aged 13-14, and upper secondary, aged 15-16). Math and Italian scores from boys and girls were averaged considering their high consistency (ranging from $\alpha=.87$ to $\alpha=.96$ ). Only INVALSI scores of natives to the regions were targeted.

\section{Geophysical variables}

Annual MJ/m² values of global solar radiation in a horizontal plane in 1994-1999 were obtained from the Italian National Agency for New Technologies, Energy, and Sustainable Economic Development (Petrarca, Cogliani \& Spinelli, 2000). This indicator uses a satellite's secondary images in the visible 
band and takes into account that the amount of radiation falling on a given area is correlated to the cloud cover of the area. Italy's territory is flanked by the Alps and crossed by the Apennines. Hence, altitude above sea level is another exogenous variable included in the present study considering that it impairs cognitive ability (León \& Avilés, 2016). Temperature in Celsius degrees for the years 2000 2009 came from ISTAT (2010); temperature was included in the research because it is an important confounding variable.

\section{Socioeconomic variables}

2012 per capita GDP per region/province came from ISTAT (2013). Percentage of 30-34 years old adults with complete tertiary education level for the years 2004-2015 and long-term unemployment share computed in 2014 were obtained from Eurostat (2016). Total fertility rate, used in previous studies considering its theoretical significance (León \& Burga-León, 2015), was not considered given its important restriction of range in Italy.

\section{Analytic strategy}

Standard OLS regression may distort the relationships by using the specificity of the predictors rather than what they have in common. For example, in the prediction of GDP from CCA, education, and employment, strong collinearity is likely; yet, the covariance between the latter variables is held constant. Since what the socioeconomic variables have in common may be theoretically more interesting than their specificities, structural equation modeling (SEM) addressing a hypothesized socioeconomic latent variable (SELV) was expected to yield more meaningful outcomes.

\section{Results}

\section{PISA scores}

Preliminary analyses. Table 1 presents inter-correlations encompassing the geophysical, socioeconomic, and PISA variables. Solar radiation correlated significantly with all study variables except altitude, temperature with all except education, and altitude only with temperature. The socioeconomic variables inter-correlated significantly, except education with per capita GDP, and the PISA scores were highly inter-correlated. The cognitive effects of solar radiation were negative, while those of temperature were positive, when both were entered into an OLS regression (Table 2). This counterintuitive result is obviously caused by strong collinearity between the variables. Therefore temperature was omitted in subsequent analyses. Cognitive effects of solar radiation and, to a lesser extent, altitude were observed (Table 3). Per capita GDP was not predictable from any variable (Table 4). Collinearity was moderately high and certainly affected these results. The observed altitude effects on CCA are consistent with León and Avilés' (2012) findings in Peru.

Table 1. Descriptive statistics and inter-correlations including PISA scores, 19 Italian regions.

\begin{tabular}{|r|l|r|r|r|r|r|c|c|c|c|c|c|}
\hline & Variable & \multicolumn{1}{|c|}{ Mean } & \multicolumn{1}{c|}{ SD } & \multicolumn{1}{c|}{1} & \multicolumn{1}{c|}{2} & \multicolumn{1}{c|}{3} & 4 & 5 & 6 & 7 & 8 & 9 \\
\hline 1 & Solar radiation & 5215.92 & 362.51 & - & & & & & & & & \\
2 & Altitude & 424.05 & 219.62 & -.36 & - & & & & & & & \\
3 & Temperature & 12.39 & 3.84 & $.93^{*}$ & $-.62^{* *}$ & - & & & & & & \\
4 & Per capita GDP & 21448.69 & 7317.90 & $-.71^{*}$ & .23 & $-.69^{*}$ & - & & & & & \\
5 & Education & 25.94 & 4.62 & $-.49^{*}$ & .16 & -.38 & .35 & - & & & & \\
6 & Unemployment share & 56.04 & 10.08 & $.83^{*}$ & -.40 & $.80^{*}$ & $-.66^{*}$ & -.42 & - & & & \\
7 & PISA male math & 494.81 & 27.05 & $-.85^{*}$ & -.03 & $-.68^{*}$ & $.56^{*}$ & $.52^{*}$ & $-.72^{*}$ & - & & \\
8 & PISA male reading & 469.76 & 22.74 & $-.81^{*}$ & .01 & $-.68^{*}$ & $.52^{*}$ & $.45^{*}$ & $-.65^{*}$ & $.97^{*}$ & - & \\
9 & PISA female math & 476.71 & 25.99 & $-.84^{*}$ & -.03 & $-.66^{*}$ & $.61^{*}$ & $.52^{*}$ & $-.76^{*}$ & $.96^{*}$ & $.92^{*}$ & - \\
10 & PISA female reading & 509.57 & 24.15 & $-.81^{*}$ & -.06 & $-.65^{*}$ & $.59^{*}$ & $.50^{*}$ & $-.68^{*}$ & $.95^{*}$ & $.94^{*}$ & $.97^{*}$ \\
\hline
\end{tabular}


${ }^{*}$ An asterisk indicates that the $95 \%$ confidence interval for the respective $t$ does not include zero.

Table 2. Standardized coefficients from OLS regressions of PISA scores on solar radiation and temperature, and regression model summary, 19 Italian regions.

\begin{tabular}{|l|c|c|c|c|}
\hline Predictor & Male Math & Male Reading & Female Math & Female Reading \\
\hline Solar radiation & $-1.67^{*}$ & $-1.39^{*}$ & $-1.67^{\star}$ & $-1.62^{*}$ \\
Temperature & $.87^{\star}$ & .62 & $.89^{*}$ & $.86^{\star}$ \\
Corrected R2 & .81 & .58 & .78 & .73 \\
Anova F & $42.69^{*}$ & $21.83^{*}$ & $36.30^{*}$ & $27.92^{*}$ \\
\hline
\end{tabular}

Notes: The variance inflation factor (VIF) reached 7.71.

*An asterisk indicates that the $95 \%$ confidence interval for the respective $t$ does not include zero.

Table 3. Standardized coefficients from OLS regressions of PISA scores on solar radiation, altitude, per capita GDP, education and unemployment share, per gender and task type, and regression model summary, 19 Italian regions.

\begin{tabular}{|l|c|c|c|c|}
\hline Predictor & Male Math & Male Reading & Female Math & Female Reading \\
\hline Solar radiation & $-.86^{*}$ & $-.95^{*}$ & $-.66^{*}$ & $-.79^{*}$ \\
Altitude & $-.41^{*}$ & $-.33^{*}$ & $-.42^{*}$ & $-.41^{*}$ \\
Per capita GDP & -.14 & -.12 & -.04 & .00 \\
Education & .13 & .06 & .13 & .12 \\
Unemployment share & -.21 & -.06 & -.35 & -.14 \\
Corrected R2 & .85 & .68 & .83 & .75 \\
Anova F & $22.26^{*}$ & $8.53^{*}$ & $21.00^{*}$ & $13.24^{*}$ \\
\hline
\end{tabular}

Notes: The variance inflation factor (VIF) ranged from 1.20 to 4.06 .

*An asterisk indicates that the $95 \%$ confidence interval for the respective $t$ does not include zero.

Table 4. Standardized coefficients from OLS regressions of per capita GDP on solar radiation, altitude, education, unemployment share, and PISA score, and regression model summary, Italy. The columns specify the type of student and PISA score predicting GDP.

\begin{tabular}{|l|c|c|c|c|}
\hline & \multicolumn{4}{|c|}{ PISA score is } \\
\cline { 2 - 5 } Predictor & Male Math & Male Reading & Female Math & Female Reading \\
\hline Solar radiation & -.95 & -.74 & -.62 & -.53 \\
Altitude & -.27 & -.13 & -.11 & -.05 \\
Education & .07 & .02 & .02 & .00 \\
Unemployment share & -.33 & -.25 & -.29 & -.24 \\
PISA score & -.54 & -.24 & -.15 & .00 \\
Corrected R2 & .41 & .38 & .36 & .36 \\
Anova F & $3.74^{*}$ & $3.44^{*}$ & $3.28^{*}$ & $3.24^{*}$ \\
\hline
\end{tabular}


Notes: VIF ranged from 1.39 to 6.83 .

${ }^{*}$ An asterisk indicates that the $95 \%$ confidence interval for the respective $t$ does not include zero. 
Hypothesis testing. A negative socioeconomic latent variable (circle) emerged in structural equation modeling (SEM) analyses from the manifest variables (yellow boxes in Figure 1). Altitude was excluded from the SEMs to simplify the models.. The results shown in Fig. 1 are consistent with Hypothesis 2 but failed to converge when Hypothesis 1 was tested; conventional standards of model fit require $X^{2} / \mathrm{df}<2$ or $3, \mathrm{CFI}>0.95$, and SRMR and RMSEA equal to or below .08. SEMs entailing math in females and math and reading in males yielded similar contrasts (Table 5).
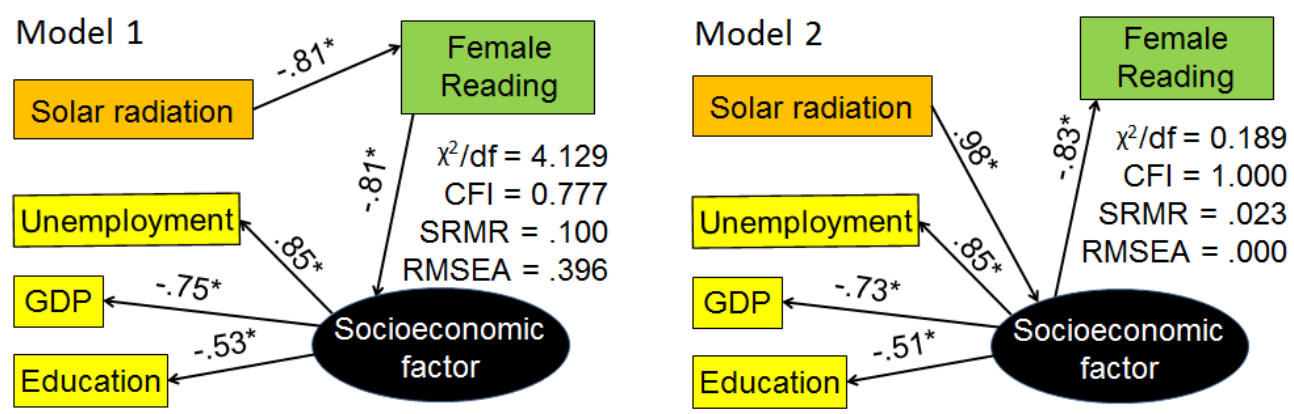

*An asterisk indicates that the $95 \%$ confidence interval for the respective $z$ does not include zero.

Fig. 1. Results of structural equation models for the relationships between solar radiation, PISA score (reading among females), and a socioeconomic latent variable in Italy.

Table 5. Results of structural equation models for the relationships between solar radiation, PISA score, and a socioeconomic latent variable (SELV) in Italy, per gender, PISA task, and model (M1, M2).

\begin{tabular}{|l|c|c|c|c|c|c|}
\hline \multirow{2}{*}{$\begin{array}{l}\text { Paths and } \\
\text { Model Fit }\end{array}$} & \multicolumn{5}{|c|}{ Gender, PISA Task, and Model } \\
\cline { 2 - 7 } & \multicolumn{2}{|c|}{ Female Math } & \multicolumn{2}{|c|}{ Male Reading } & \multicolumn{2}{c|}{ Male Math } \\
\cline { 2 - 7 } & M1 & M2 & M1 & M2 & M1 & M2 \\
\hline Radiation $\rightarrow$ PISA & $-.84^{*}$ & & $-.81^{*}$ & & $-.85^{*}$ & \\
PISA $\rightarrow$ SELV & $-.87^{\star}$ & & $-.74^{*}$ & & $-.83^{*}$ & \\
Radiation $\rightarrow$ SELV & & $.96^{*}$ & & $1.00^{*}$ & & $.98^{*}$ \\
SELV $\rightarrow$ PISA & & $-.87^{*}$ & & $-.81^{*}$ & & $-.87^{*}$ \\
\hline X2/df & 2.091 & 0.193 & 6.261 & 0.243 & 2.585 & 0.376 \\
CFI & 0.908 & 1.000 & 0.796 & 1.000 & 0.870 & 1.000 \\
SRMR & .077 & .023 & .116 & .026 & .086 & .030 \\
RMSEA & .234 & .000 & .336 & .000 & .282 & .000 \\
\hline
\end{tabular}

Notes: Relationships between SELV and its components are omitted; all were significant.

${ }^{*}$ An asterisk indicates that the $95 \%$ confidence interval for the respective $z$ does not include zero. 


\section{INVALSI scores}

Preliminary analyses. The OLS correlational and regression analyses including INVALSI scores (Tables 6-9) were identical in structure to those involving PISA scores.

Hypothesis testing. Model 1 SEMs failed to achieve satisfactory standards of fit whereas Model 2 emerged well adjusted, except in $5^{\text {th }}$ grade of primary school. Results are shown in Table 10 . Refer to Figure $1 \mathrm{for}$ structure of the model, with INVALSI scores substituting for female reading.

Table 6. Descriptive statistics and inter-correlations including INVALSI scores, Italy.

\begin{tabular}{|c|c|c|c|c|c|c|c|c|c|c|c|c|c|}
\hline & Variable & Mean & SD & 1 & 2 & 3 & 4 & 5 & 6 & 7 & 8 & 9 & 10 \\
\hline 1 & Solar radiation & 5215.92 & 362.51 & - & & & & & & & & & \\
\hline 2 & Altitude & 424.05 & 219.62 & -.36 & - & & & & & & & & \\
\hline 3 & Temperature & 12.39 & 3.84 & $.93^{*+*}$ & $-.62^{* *}$ & & & & & & & & \\
\hline 4 & Per capita GDP & 21448.69 & 7317.90 & $-.71^{*+*}$ & .23 & $-.69^{* *}$ & - & & & & & & \\
\hline 5 & Education & 25.94 & 4.62 & $-.49^{*}$ & 16 & -.38 & .35 & - & & & & & \\
\hline 6 & Unemployment share & 56.04 & 10.08 & $.83^{*+*}$ & $-.40^{+}$ & $.80^{* * *}$ & $-.66^{* *}$ & $-.42^{+}$ & - & & & & \\
\hline 7 & PISA & 489.90 & 25.85 & $-.85^{* * t}$ & -.03 & $-.69^{* *}$ & $.60^{* *}$ & $.50^{*}$ & $-.74^{* *+x}$ & - & & & \\
\hline 8 & INVALSI 2 2nd grade primary & 201.91 & 5.47 & $-.51^{*}$ & 18 & $-.44^{*}$ & .15 & .34 & -.35 & $.62^{* *}$ & - & & \\
\hline 9 & INVALSI $5^{\text {th }}$ grade primary & 202.90 & 5.33 & $-.78^{* * *}$ & .03 & $-.55^{\star}$ & .40 & $.75^{\text {tot }}$ & $-.52^{\star}$ & $.81^{*+*}$ & $.61^{* *}$ & - & \\
\hline 10 & INVALSI lower secondary & 202.92 & 10.27 & $-.79^{* * *}$ & 13 & $-.67^{* *}$ & $.51^{*}$ & $.57^{* *}$ & $-.76^{* * *}$ & $.90^{*+*}$ & $.55^{* *}$ & $.79^{* * *+}$ & - \\
\hline 11 & INVALSI upper secondary & 201.41 & 11.21 & $-.78^{*+*+}$ & -.11 & $-.62^{* *}$ & $.53^{*}$ & $.55^{* *}$ & $-.64^{* *}$ & $.88^{*+*}$ & $.43^{*}$ & $.75^{* * * *}$ & $.72^{*+*}$ \\
\hline
\end{tabular}

${ }^{*} p<.05,{ }^{* *} p<.01,{ }^{* * *} p<.001$.

Table 7. Standardized coefficients from OLS regressions of INVALSI scores on solar radiation and temperature, and regression model summary; 19 Italian regions.

\begin{tabular}{|l|c|c|c|c|}
\hline Predictor & $2^{\text {nd }}$ primary & $5^{\text {th }}$ primary & Lower secondary & Upper secondary \\
\hline Solar radiation & -.75 & $-1.84^{*}$ & $-1.27^{*}$ & $-1.53^{*}$ \\
Temperature & .26 & $1.16^{*}$ & .51 & .80 \\
Corrected $\mathrm{R}^{2}$ & .18 & .71 & .62 & .66 \\
Anova F & 3.26 & $25.44^{*}$ & $17.59^{*}$ & $20.30^{*}$ \\
\hline
\end{tabular}

Notes: The variance inflation factor (VIF) reached 7.71.

*An asterisk indicates that the $95 \%$ confidence interval for the respective $t$ does not include zero.

Table 8. Standardized coefficients from OLS regressions of INVALSI scores on solar radiation, altitude, per capita GDP, education, and unemployment share, per school level, and regression model summary; 19 Italian regions. 


\begin{tabular}{|l|c|c|c|c|}
\hline Predictor & $2^{\text {nd }}$ primary & $5^{\text {th }}$ primary & Lower secondary & Upper secondary \\
\hline Solar radiation & -.86 & $-.95^{\star}$ & -.52 & -.78 \\
Altitude & .01 & -.25 & -.24 & $-.46^{*}$ \\
Per capita GDP & -.42 & $-.25^{\star}$ & -.18 & -.09 \\
Education & .12 & $.51^{*}$ & .23 & .21 \\
Unemployment share & .15 & .22 & -.45 & -.15 \\
Corrected R2 & .15 & .84 & .69 & .77 \\
Anova F & 1.72 & $21.23^{*}$ & $9.73^{*}$ & $14.48^{*}$ \\
\hline
\end{tabular}

Notes: The variance inflation factor (VIF) ranged from 1.20 to 4.06 .

*An asterisk indicates that the $95 \%$ confidence interval for the respective $t$ does not include zero.

Table 9. Standardized coefficients from OLS regressions of per capita GDP on solar radiation, altitude, education, unemployment share, and INVALSI scores, and regression model summary, Italy. The columns specify the type of student taking the INVALSI test.

\begin{tabular}{|l|c|c|c|c|}
\hline Predictor & $2^{\text {nd }}$ primary & $5^{\text {th }}$ primary & Lower secondary & Upper secondary \\
\hline Solar radiation & -.70 & -1.17 & -.67 & -.71 \\
Altitude & -.04 & -.23 & -.13 & -.17 \\
Education & .04 & .40 & .08 & .06 \\
Unemployment share & -.17 & -.02 & -.38 & -.27 \\
INVALSI score & -.27 & -.78 & -.34 & -.25 \\
Corrected R & .43 & .48 & .40 & .37 \\
Anova F & $4.02^{*}$ & $4.75^{*}$ & $3.64^{*}$ & $3.39^{*}$ \\
\hline
\end{tabular}

Notes: VIF ranged from 1.40 to 8.23 .

${ }^{*}$ An asterisk indicates that the $95 \%$ confidence interval for the respective $t$ does not include zero.

Table 10. Results of structural equation models for the relationships between solar radiation, INVALSI score, and a socioeconomic latent variable (SELV) in Italy, per school level and model (M1, $\mathrm{M} 2)$. 


\begin{tabular}{|c|c|c|c|c|c|c|c|c|}
\hline \multirow{3}{*}{$\begin{array}{l}\text { Paths and } \\
\text { Model Fit } \\
\text { Indicators }\end{array}$} & \multicolumn{8}{|c|}{ School Level and Model } \\
\hline & \multicolumn{2}{|c|}{$2^{\text {nd }}$ Primary } & \multicolumn{2}{|c|}{$5^{\text {th }}$ Primary } & \multicolumn{2}{|c|}{ Lower Secondary } & \multicolumn{2}{|c|}{ Upper Secondary } \\
\hline & M1 & M2 & M1 & M2 & M1 & M2 & M1 & M2 \\
\hline $\begin{array}{l}\text { Radiation } \rightarrow \text { INV. } \\
\text { INV. } \rightarrow \text { SELV } \\
\text { Radiation } \rightarrow \text { SELV } \\
\text { SELV } \rightarrow \text { INV. }\end{array}$ & $\begin{array}{l}-.51^{*} \\
-.37^{*}\end{array}$ & $\begin{array}{l}1.00^{*} \\
-.51\end{array}$ & $\begin{array}{l}-.75^{*} \\
-.90^{*}\end{array}$ & $\begin{array}{l}1.01^{*} \\
-.75^{*}\end{array}$ & $\begin{array}{l}-.79^{*} \\
-.85^{*}\end{array}$ & $\begin{array}{r}.95^{*} \\
-.84^{*}\end{array}$ & $\begin{array}{l}-.78^{*} \\
-.78^{*}\end{array}$ & $\begin{array}{c}.98^{*} \\
-.80^{*}\end{array}$ \\
\hline$x^{2 / d f}$ & 5.707 & 0.755 & 6.826 & 3.803 & 2.990 & 0.805 & 3.429 & 0.485 \\
\hline CFI & 0.446 & 1.000 & 0.574 & 0.795 & 0.831 & 1.000 & 0.777 & 1.000 \\
\hline SRMR & .254 & .065 & 178 & .112 & 101 & .045 & .121 & .042 \\
\hline RMSEA & .485 & .000 & .540 & .374 & .315 & .000 & .348 & .000 \\
\hline
\end{tabular}

Notes: Relationships between SELV and its components are omitted; all were significant.

* An asterisk indicates that the $95 \%$ confidence interval for the respective $z$ does not include zero.

\section{Discussion}

Lynn's (2010) attribution of the north-to-south decay of per capita GDP in Italy to inherited intelligence is contradicted by Study 1's results of regression analyses and, especially, SEMs demonstrating that Italian solar radiation impairs PISA and INVALSI scores through a socio-economic latent variable (SELV) defined by unemployment, per capita GDP, and education. The Italian correlations between per capita GDP and PISA and INVALSI scores reported by Lynn (2010) and others and found here are attributable to the radiation $\rightarrow$ SELV $\rightarrow I Q$ mediation.

\section{Study 2}

Michael A. Woodley of Menie (peer review received March 20, 2017) suggested an alternative explanation: UVR levels could be simply a proxy for ancestry, specifically with respect to markers such as skin reflectance, which is an adaptation to dealing with UVR (Jablonski \& Chaplin, 2010). Woodley of Menie suggested also that the mediating role of socioeconomic status in the latitude-IQ relationship could be confounded with life history strategy. J. Phillipe Rushton championed the idea that highly stable environments such as those found in more northerly regions of the globe facilitated the evolution of slower life histories expressed in delayed physical development and sexual initiation and associated with higher parental investment in the offspring and higher intelligence. Figueredo et al. (2017), using a large sample of countries, have shown that climatic and biotic factors impact biometric markers of life history, triggering changes in macroeconomic diversification and human capital.

Woodley of Menie's interpretation of the Study 1 findings can be tested in a population whose skin reflectance at birth is uncorrelated with latitude. This is the case of White children living at different latitudes in the United States; there is no evidence that their skin reflectance decreases from New Orleans and Miami to Minneapolis and Boston, at least on parts of the skin protected from the sun. Thus, if results similar to those of Study 1 were found among White Americans, the arguments of Woodley of Menie would be weakened and, for the sake of parsimony, the Italian results of Study 1 could be viewed as evidence of cognitive effects of UVR mediated by socioeconomic variables.

\section{Methods}

\section{Subjects}


The study targeted the 48 contiguous USA states; Alaska and Hawaii are extreme latitudinal and longitudinal outliers. Only White children were considered. The categorization as White depends on the individual's self-identification, in turn based on his/her birth certificate. Whereas American babies are registered as Hispanics considering their mother's last name, Whites are distinguished from other ethnic groups (Blacks, Asians, Native Americans) by phenotypic traits such as skin color and eye shape.

\section{Standardized student evaluations}

This study used math and reading scores from the U.S. National Assessment of Educational Progress (NAEP) report (National Center for Education Statistics/Institute of Education Sciences, 2016). NAEP is the gold standard of measuring student achievements in the United States. The assessment stays essentially the same from year to year; at the state level, assessment is in public schools only. Math and reading scores of White children in $4^{\text {th }}$ and $8^{\text {th }}$ grade obtained in 2015 were used. NAEP does not provide differentiated scores by gender within ethnic categories.

\section{Geophysical variables}

The Climate Prediction Center of the National Weather Service (2016) offers information on the UV Index under clear sky for each largest city per state with the exception of two states in which the capital city is targeted. Detailed information on the yearly number of days in which a specific UVIndex level occurred is provided by the Service, the levels of radiation being: extreme $=11-15$, very high $=8-10$, high $=6-7$, moderate $=3-5$, and low $=0-2$. We calculated a weighted sum of the number of days in which extreme $\left({ }^{*} 5\right)$, very high $\left({ }^{*} 4\right)$, high $\left({ }^{*} 3\right)$, moderate $\left({ }^{*} 2\right)$, and low $\left({ }^{*} 1\right)$ levels of radiation occurred in 2015. Mean temperature per state in Fahrenheit degrees for 2015 was obtained from the National Weather Service (2017).

\section{Socioeconomic variables}

Per capita income per state in 2015 came from the Bureau of Economic Analysis of the U.S. Department of Commerce (2016), which uses data from the U.S. National Census. Percentage of 25 year old adults and older with bachelor's degree in 2015 was obtained from the American Community Survey (U.S. Census Bureau, 2016) and unemployment rate for 2015 from the Bureau of Labor Statistics (U.S. Department of Labor, 2016). Percentage of White population in the state came from the 2010 U.S. Census (U.S. Census Bureau, 2011); this variable is needed as control for the weight of ethnic minorities in the socioeconomic variables of the study.

\section{Results}

\section{Preliminary analyses}

Significant correlations emerged between the geophysical and social variables, as well as between the cognitive variables; on the other hand, unemployment and percent White presented inconsistent correlations and UV Index and temperature only correlated with cognitive scores in $8^{\text {th }}$ grade; the correlations of unemployment and percent White with cognitive scores were generally nonsignificant (Table 11). Like in Italy, the regression coefficients for the cognitive scores on UV Index were negative and those on temperature were positive (Table 12). UV Index did not predict cognitive ability when socioeconomic factors were controlled (Table 13). However, UV Index along with NAEP $4^{\text {th }}$ grade reading predicted income when the other variables were controlled (Table 14). Education is the only consistent predictor across models in both tables. 
Table 11. Descriptive statistics and intercorrelations including NAEP scores, United States.

\begin{tabular}{|c|c|c|c|c|c|c|c|c|c|c|c|c|}
\hline & Variable & Mean & SD & 1 & 2 & 3 & 4 & 5 & 6 & 7 & 8 & 9 \\
\hline 1 & UV Index weighted mean & 904.11 & 187.94 & - & & & & & & & & \\
\hline 2 & Temperature & 51.41 & 7.98 & $.90^{\star}$ & - & & & & & & & \\
\hline 3 & Per capita median income & 46212.67 & 7083.67 & $-.39^{*}$ & $-.34^{*}$ & - & & & & & & \\
\hline 4 & Education (Bachelor's degree) & 18.24 & 2.81 & $-.48^{*}$ & $-.44^{*}$ & $.70^{*}$ & - & & & & & \\
\hline 5 & Unemployment rate & 5.00 & 1.03 & $.49^{*}$ & $.57^{\star}$ & -.22 & $-.50^{*}$ & - & & & & \\
\hline 6 & Percent White & 82.10 & 9.51 & $-.55^{\star *}$ & $-.66^{*}$ & .01 & .20 & $-.55^{\star}$ & - & & & \\
\hline 7 & $4^{\text {th }}$ grade Math & 247.40 & 4.59 & -.15 & -.11 & $.55^{*}$ & $.63^{*}$ & $-.32^{*}$ & -.01 & - & & \\
\hline 8 & $4^{\text {th }}$ grade Reading & 230.67 & 4.91 & -.14 & -.01 & $.71^{*}$ & $.67^{*}$ & -.15 & -.17 & $.79^{*}$ & - & \\
\hline 9 & $8^{\text {th }}$ grade Math & 290.15 & 6.35 & $-.37^{*}$ & $-.34^{*}$ & $.62^{*}$ & $.80^{*}$ & $-.38^{*}$ & .10 & $.87^{\star}$ & $.75^{\star}$ & - \\
\hline 10 & $8^{\text {th }}$ grade Reading & 272.54 & 3.96 & $-.38^{*}$ & $-.27^{+}$ & $.71^{*}$ & $.81^{*}$ & -.24 & .09 & $.71^{*}$ & $.82^{*}$ & $.85^{*}$ \\
\hline
\end{tabular}

${ }^{*}$ An asterisk indicates that the $95 \%$ confidence interval for the respective $t$ does not include zero. Here you also use ${ }^{*}$ and + .

Table 12. Standardized coefficients from OLS regressions of NAEP scores on UV Index and temperature, and regression model summary, United States.

\begin{tabular}{|l|c|c|c|c|}
\hline & \multicolumn{2}{|c|}{ Fourth Grade } & \multicolumn{2}{c|}{ Eighth Grade } \\
\hline Predictor & Math & Reading & Math & Reading \\
\hline UV Index & -.31 & $-.68^{*}$ & -.37 & $-.68^{*}$ \\
Temperature & .18 & .60 & -.00 & .34 \\
Corrected R2 & -.01 & .05 & .10 & .13 \\
Anova F & 0.69 & 2.14 & $3.60^{*}$ & $4.35^{*}$ \\
\hline
\end{tabular}

Note: The VIF $=5.259$.

"An asterisk indicates that the $95 \%$ confidence interval for the respective $t$ does not include zero.

Table 13. Standardized coefficients from OLS regressions of NAEP scores on UV radiation, income, education, and percent White, per school grade and type of task, and regression model summary in the U.S., 48 states.

\begin{tabular}{|l|c|c|c|c|}
\hline Predictor & $4^{\text {th }}$ math & $4^{\text {th }}$ reading & $8^{\text {th }}$ math & $8^{\text {th }}$ reading \\
\hline UV Index & .21 & .17 & .00 & .02 \\
Income & .22 & $.44^{*}$ & .10 & .28 \\
Education & $.58^{*}$ & $.47^{*}$ & $.74^{*}$ & $.63^{*}$ \\
Percent White & -.02 & -.17 & -.04 & -.03 \\
Corrected R2 & .41 & .60 & .61 & .67 \\
Anova F & $9.11^{*}$ & $18.30^{*}$ & $19.38^{*}$ & $24.41^{*}$ \\
\hline
\end{tabular}

Notes: VIF ranged from 1.55 to 2.21 .

*An asterisk indicates that the $95 \%$ confidence interval for the respective $t$ does not include zero. 
Table 14. Standardized coefficients from OLS regressions of income on UV Index, education, unemployment share, and NAEP scores, and regression model summary, USA. The columns specify the type of student and NAEP score predicting GDP. U.S., 48 states.

\begin{tabular}{|l|c|c|c|c|}
\hline Predictor & $4^{\text {th }}$ math & $4^{\text {th }}$ reading & $8^{\text {th }}$ math & $8^{\text {th }}$ reading \\
\hline UV Index & -.23 & $-.24^{*}$ & -.20 & -.20 \\
Education & $.51^{*}$ & .31 & $-.54^{*}$ & .34 \\
Percent White & -.22 & -.11 & -.22 & -.19 \\
NAEP score & .19 & $.45^{*}$ & .13 & .38 \\
Corrected R & .51 & .59 & .49 & .54 \\
Anova F & $13.10^{*}$ & $17.79^{*}$ & $12.42^{*}$ & $14.84^{*}$ \\
\hline
\end{tabular}

Notes: VIF ranged from 1.46 to 3.23 .

"An asterisk indicates that the $95 \%$ confidence interval for the respective $t$ does not include zero.

Hypothesis testing

Both models 1 and 2 tested in Italy yielded results of very poor fit in the United States, even when the average 2011-2015 unemployment rate was considered (not shown). However, a positive socioeconomic latent variable (SELV) emerged and fit indices of structural equation models improved when unemployment rate was excluded from the analyses. Excluding unemployment, Model 1 consistently yielded poor adjustment whereas Model 2 generated adequate fit in $8^{\text {th }}$ grade, albeit not in $4^{\text {th }}$ grade. Fig. 2 presents results for $8^{\text {th }}$ grade math, and Table 15 presents results for the remaining subjects and grades. The failure of Hypothesis 2 in $4^{\text {th }}$ grade is similar to the case of $5^{\text {th }}$ grade in Italy. It can be noticed also that the UV Index $\rightarrow$ SELV and UV Index $\rightarrow$ NAEP score path coefficients were considerably smaller than those observed in Italy.
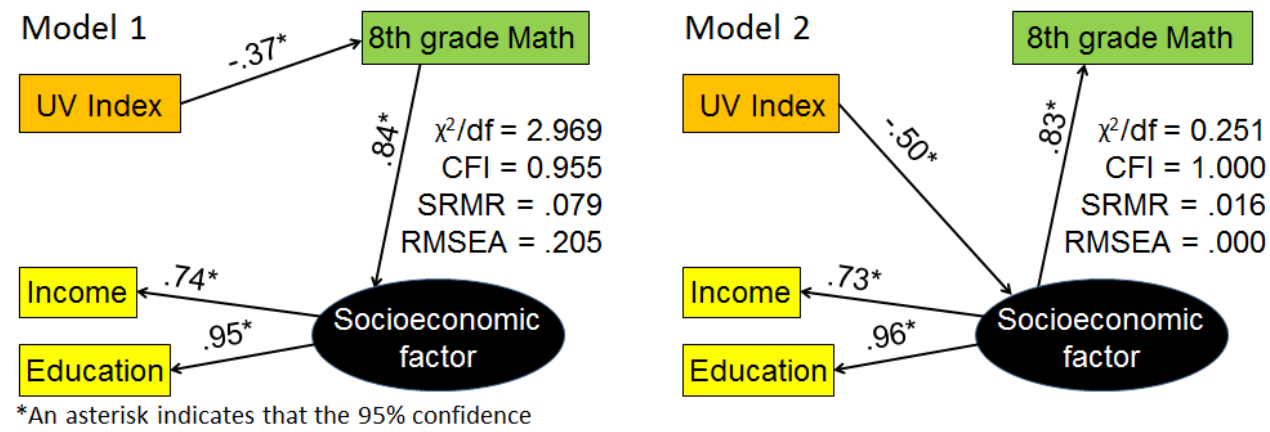

interval for the respective $z$ does not include zero.

Fig. 2. Results of structural equation models for the relationships between UV Index, math score in $8^{\text {th }}$ grade, and a socioeconomic latent variable in the United States.

Table 15. Results of structural equation models for the relationships between UV Index, NAEP scores, and a socioeconomic latent variable (SELV) in the United States, per school grade, school subject, and model (M1, M2). 


\begin{tabular}{|c|c|c|c|c|c|c|}
\hline & \multicolumn{6}{|c|}{ School Grade, Subject, and Model } \\
\hline \multirow{2}{*}{$\begin{array}{l}\text { Paths and Model Fit } \\
\text { Indicators }\end{array}$} & \multicolumn{2}{|c|}{$4^{\text {th }}$ Grade Math } & \multicolumn{2}{|c|}{$4^{\text {th }}$ Grade Reading } & \multicolumn{2}{|c|}{$8^{\text {th }}$ Grade Reading } \\
\hline & M1 & M2 & M1 & M2 & M1 & M2 \\
\hline $\begin{array}{l}\text { Radiation } \rightarrow \text { INV. } \\
\text { INV. } \rightarrow \text { SELV } \\
\text { Radiation } \rightarrow \text { SELV } \\
\text { SELV } \rightarrow \text { INV. }\end{array}$ & $\begin{array}{l}-.15 \\
.71^{*}\end{array}$ & $\begin{array}{r}-.49^{*} \\
.95^{*}\end{array}$ & $\begin{array}{c}.14 \\
.82^{*}\end{array}$ & $\begin{array}{c}-.43^{*} \\
.84^{*}\end{array}$ & $\begin{array}{l}-.38^{*} \\
.91^{*}\end{array}$ & $\begin{array}{c}-.49^{*} \\
.91^{*}\end{array}$ \\
\hline$x^{2} / d f$ & 7.341 & 2.272 & 9.132 & 5.651 & 2.954 & 0.916 \\
\hline CFI & 0.812 & 0.962 & 0.804 & 0.888 & 0.958 & 1.000 \\
\hline SRMR & 156 & .058 & 154 & .075 & .070 & .023 \\
\hline RMSEA & .367 & .165 & .416 & .315 & .204 & .000 \\
\hline
\end{tabular}

Notes: Relationships between SELV and its components are omitted; all were significant.

${ }^{*}$ An asterisk indicates that the $95 \%$ confidence interval for the respective $z$ does not include zero.

\section{Discussion}

The findings of Study 2 cannot be attributed to a genetically determined life history; there is no evidence of genetic differences along latitude among White Americans. Rather, the findings are consistent with the theory that UVR reduces industriousness through oxidative stress; less industrious populations can be expected to create poorer material and cultural environments for the child, reducing his/her opportunities for cognitive growth. On the other hand, a slower life history associated with higher absolute latitudes should not be ruled out; Table 1 of Finer and Kost (2011) reveals that adolescents' undesired pregnancies increase with proximity to the equator in the United States. But this may be explained by UVR's facilitated production of vitamin D (Engelsen et al., 2005), which in turn favors secretion of testosterone and estrogen (Jones, Strungnell, \& DeLucca, 1998; Wang et al., 2015).

\section{Study 3}

Studies 1 and 2 were criticized on two main grounds, one theoretical and the other methodological. Reviewer 1 (peer review received September 13,2017) stated that one should not talk about intelligence if intelligence tests have not been used in the research; there are studies which show that achievement and IQ tests do not measure the same construct. But such studies were based on individual scores, not aggregate scores. Reviewer 1's assertion is oblivious to Rindermann's (2007a) demonstration that a $g$ factor explained $94-95 \%$ of the variance in intelligence tests scores (Raven Progressive Matrices, Wechsler intelligence scales) and scores from standardized student evaluations (PISA, TIMMS, PIRLS) using 194 countries as units of analysis, and the ensuing discussion (Open Peer Commentary, 2007; Rindermann, 2007b). Reviewer 1 seems to have equated intelligence with fluid intelligence. He/she objected to the use of the term intelligence to refer to achievement test scores considering the efforts made by psychologists to exclude or reduce the impact of social and cultural factors in IQ measurement. Achievement tests would be more exposed to the influence of social and cultural factors. To uphold his/her view, Reviewer 1 said: "Actually, D'Amico et al. (2012) demonstrated that there are no IQ differences among children from the south and from the north of Italy when the Raven culture-free test is used".

Again, this assertion is oblivious to the fact that there were methodological problems in the D'Amico et al. study. These researchers compared their Raven data obtained in Palermo (Sicilia) 
excluding children with sociocultural disadvantages with data from the Cornoldi et al. (2010) standardization of the Raven test in the north and central-south of Italy, which did not exclude children with sociocultural disadvantages. The Sicilian group probably took advantage of the D'Amico et al. sampling methodology and this may explain the lack of latitudinal differences found in the northsouth comparison using the Raven test. But even if the D'Amico et al. findings were correct and demonstrated that there are no differences in fluid intelligence between the Italian provinces, this would not contradict the Study 1 conclusions. The Study 1 results suggested that the link of UVR was more direct with non-cognitive traits that led to differences in socio-economic development, and CCA differences were a secondary outcome. Reviewer 2 (peer review received September 13, 2017), in turn, objected to the use of SEMs with very small sample sizes (only 21 regions in Italy). The concept of fluid intelligence is easily confounded with the nature-nurture debate. Reviewer 1 probably was assuming an inherited intelligence uncontaminated by environmental variables. Thus, Study 3 was designed to distinguish racial and UVR determinants of Brazilian PISA scores. Fuerst and Kirkegaard (2016a) found in Brazil a correlation of .74 between European ancestry and CCA. If the Lynn hypothesis is correct, European ancestry should explain the Brazilian PISA scores when the UVR - European ancestry relationship is controlled. Like in the United States (León \& Hassall, 2017), African slaves were brought to work in equatorial plantations of Brazil whereas Europeans probably preferred to settle far from the equator. Given this likely race-latitude correlation, the Fuerst and Kirkegaard (2016) findings on the race-IQ linkage may have been spurious. On the other hand, if the present authors' hypothesis is correct, UVR should explain the PISA scores through SELV holding European ancestry constant. Regarding Reviewer 2's comments, an extension of the research to a third country, Brazil, represents an increased probability of showing the robustness of the observed relationships despite the small number of cases in the individual studies.

\section{Methods}

\section{Subjects}

The study targeted the 27 states of Brazil, but the federal capital (Brasilia) was excluded because it lacked racial data. Hence, the actual $\mathrm{N}$ was 26.

\section{Standardized student assessments}

This study used math, reading, and science scores from successive PISA rounds in Brazil (2009, 2012, 2015). Lynn et al. (2017, pp. 522-523) described as follows the methods used to obtain an aggregate PISA value from 62,082 Brazilian students:

"- The plausible values (five in 2009 and 2012 and ten in 2015) of each area (mathematics, reading and science) were obtained by state and for each of the three years.

- The average of plausible values was calculated for each state and year.

- The average of the total scores was calculated by state and year.

- The average of the three years was calculated for each state with weighting by sample size, which was different in different years."

Geophysical variables

UVR per state in 2013 was obtained from Schalka et al. (2014). The data were about a distribution of maximum UVR in the country on a day in August 2013.

Socioeconomic variables 
Poverty per state in 2000 was represented by the proportion of individuals with per capita household income equal to or less than the equivalent of $\$ 70$ per month. Other state-level variables were mortality of children under 5 years old in 2000 and percentage of adults 25 years and older with bachelor's degree in 2000. All three measures were obtained from Atlas Brasil (2014).

\section{European ancestry}

Fuerst and Kirkegaard (2016) averaged the state admixture values reported in Rodrigues de Moura et al.'s (2015) meta-analysis for 16 Brazilian states and complemented the data with estimates for the other 10 states using average values for the five major Brazilian regions.

\section{Analytic strategy}

Structural equation modeling (SEM) was preferred to hierarchical regression analysis considering its ability to capture the common variance of variables.

\section{Results}

Table 16 presents the inter-correlations between the study variables; these are similar to those found in Italy and the United States. Results of hypothesis testing are shown in Figure 3. The Lynn hypothesis (PISA $\rightarrow$ SELV) is represented in Fig. 3A whereas the alternative hypothesis (SELV $\rightarrow$ PISA) appears in Fig. 3B. The Study 3 results clearly impinge on the validity of the hypotheses.

Table 16. Descriptive statistics and intercorrelations, 26 Brazilian provinces. All correlations are statistically significant at the $p<.05$ level.

\begin{tabular}{|l|l|r|r|r|r|r|r|c|}
\hline & Variable & Mean & \multicolumn{1}{|c|}{ SD } & 1 & 2 & 3 & 4 & 5 \\
\hline 1 & UV radiation & 9.48 & 2.13 & - & & & & \\
2 & Average PISA score & 388.49 & 19.11 & -.82 & - & & & \\
3 & Poverty & 82.73 & 10.49 & .78 & -.83 & - & & \\
4 & Higher education & 10.08 & 4.90 & -.74 & .68 & -.79 & - & \\
5 & Infant mortality & 57.42 & 19.22 & .78 & -.79 & .92 & -.70 & - \\
6 & European ancestry & 0.60 & 0.11 & -.79 & .73 & -.65 & .69 & -.61 \\
\hline
\end{tabular}
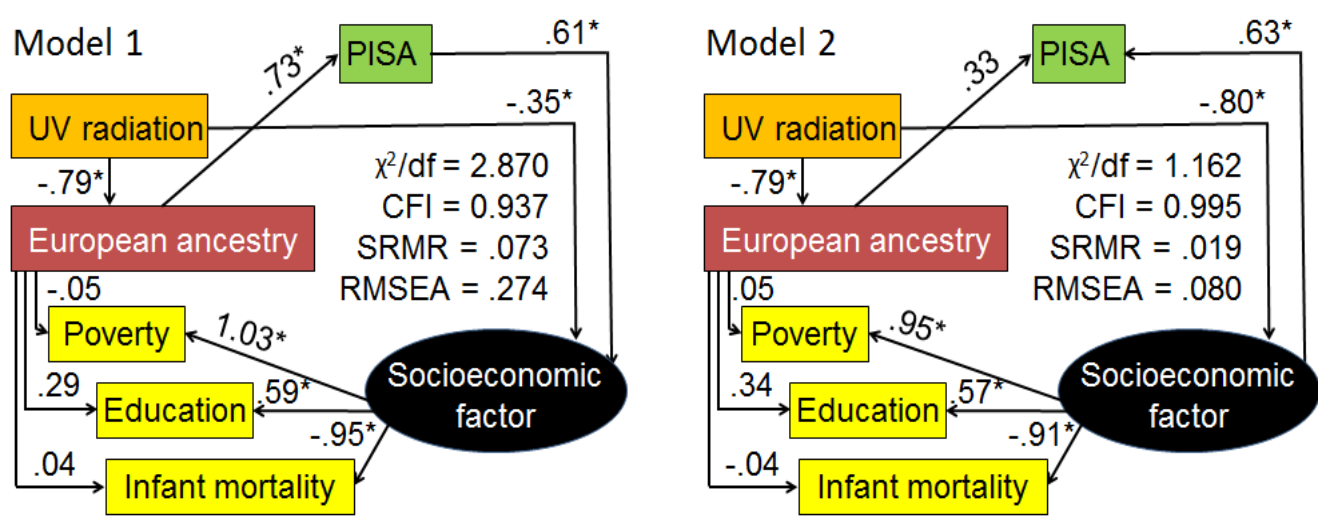
Fig. 3. Results of structural equation models for the relationships between UV radiation, average PISA score, and a socioeconomic latent variable in Brazil.

\section{Discussion}

In Model 1, the European ancestry $\rightarrow$ PISA path coefficient was significant, but the model exhibited a lack of fit. In this model, the path coefficient is the same as the correlation because there is only one arrow going to PISA score. In Model 2 , the European ancestry $\rightarrow$ PISA path coefficient was not significant and the model exhibited satisfactory indicators of fit. In this case the European $\rightarrow$ PISA path is much smaller because the correlation of PISA score with the socioeconomic factor is higher than its correlation with European. These results demonstrate that the UV radiation $\rightarrow$ SELV $\rightarrow$ PISA chain of effects is more credible than the European ancestry $\rightarrow$ PISA $\rightarrow$ SELV one and are consistent with those of Study 1 in Italy and Study 2 in the United States. The findings also suggest that Fuerst and Kirkegaard (2016a, 2016b) should reanalyze their within-country Latin American data considering the UVR variable.

\section{General Discussion}

A new theory explains the results that Lynn attributed to genetics and his Italian debaters assigned to historical factors: the present findings point to geophysics as the ultimate antecedent. The whole set of results in the literature is explainable by UV photons impairing socio-economic development (measured as a socio-economic latent variable, SELV), which in turn affects CCA. Whereas the radiation $\rightarrow$ SELV causal path may take a number of generations to materialize as culture, the greater cognitive impact of latitude observed among adolescents than children (Studies 1 and 2; Daniele \& Malanima, 2011; Robinson et al., 2011) suggests a cumulative process of environmental cognitive shaping at the individual level.

This explanation needs enrichment to account for the stronger radiation $\rightarrow$ SELV path coefficients and better-fitted radiation $\rightarrow$ SELV $\rightarrow$ CCA models seen in Italy than in the USA. Since phenotypes such as eye and hair color differentiate northern and southern Italians but not northern and southern White Americans, ancestry emerges as a strong candidate to have determined the difference. UVR may have influenced Italian intelligence genes by creating conditions for genetic selection, in the same way it determined the change from dark to light skin when Homo sapiens left Africa (Jablonski \& Chaplin, 2010). Ancestors of contemporary Italians probably adapted to the different levels of UVR in the peninsula during millennia; the ancestors of middle Europeans and Greeks, Near Easterners, and North Africans, in turn, adapted to different levels of UVR in their respective original habitats and then contributed further to north-south differentiation among Italians through admixture. The genetic adaptation of White Americans to the different levels of UVR in the United States is probably nil. Thus, whereas in the USA the first term of the IQ equation may be limited to contemporary + centuries-old radiation, in Italy it encompasses contemporary + centuriesold + millennial radiation.

The conceptual differentiation between genetic, cultural, and individual adaptations is needed to address recent criticism directed at UVR theory of CCA. In his peer review, Woodley of Menie argued that

"Whites whose ancestors have moved to countries closer to the equator (such as Afrikaners in South Africa) have IQs that are higher than those of the native Blacks ... The UV radiation stress model would predict that their cognitive ability should have dropped in response to enhanced UV exposure, and should therefore be equal to that of the Black 
population - as both groups are subject to exactly the same environmental treatment effect, which is not the case. So the model is simply false."

This assertion fails to acknowledge that CCA is multi-determined. Actually, León and Burga-León (2015) noted that UVR increases production of vitamin D and, through it, dopamine and speculated on millenary cognitive effects of ancient genetic and cultural adaptations to the winterly scarcity of vitamin $D$ and dopamine at higher absolute latitudes (ALs):

"... as AL increased, the decaying availability of dopamine could have made adaptive mutations which augmented dopamine brain receptors and generated new neural circuits; dopamine is involved in the regulation of attention which contributes to anticipatory processes necessary for preparing voluntary action consequent upon intention ..." (p. 224).

Afrikaners plausibly brought such likely evolved receptors and neural connections into Africa and there is no reason to assume that climate is capable of changing them in a few generations. Genetic and situational determinants of CCA are not mutually exclusive, but the influence of contemporary UVR on Afrikaners must be tested by comparison with equivalent British and Netherlander samples rather than with native Blacks.

There is also a need for placing a recent report in its proper context. León and Burga-León (2017), based on NAEP data, found a well-fitted UV Index $\rightarrow$ CCA $\rightarrow$ per capita income SEM which contrasted with a maladjusted UV Index $\rightarrow$ per capita income $\rightarrow$ CCA SEM. Their sample was representative of the U.S. population - i.e., including African Americans and Hispanics. Such minorities are poorer than Whites, present lower IQ levels, and are more prevalent in the southern than northern United States - which makes such results non-comparable with those of Study 2.

The evidence supplied here, which came from small samples but can be regarded as robust given its simultaneous emergence in three countries, should put an end to the Lynn Italian debate. First, the evidence strongly indicates that the north-south differences in wealth observed in Italy are not attributable to cognitive differences; rather, causality appears to run the opposite way. Second, the evidence points to UVR as the ultimate determinant of the geographic variation in CCA and wealth seen in that country. Third, situational and genetic effects appear to combine with UVR exposure to produce the outcome.

The evidence should lead the reader to question cognitive capitalism's postulate that national CCA causes country wealth; the opposite is more consistent with the evidence, albeit reciprocal causation cannot be ruled out. The study results can be expected also to encourage research that evaluates the negative impact of UVR on CCA and the negative impact of UVR on industriousness at the individual physiological-psychological level. Rigorous new evidence is needed to further test UVR theory.

\section{References}

Aruoma, O. I. (1998). Free radicals, oxidative stress, and antioxidants in human health and disease. Journal of the American Oil Chemists' Society, 75, 199-212.

Atlas Brasil (2013). Atlas of Human Development in Brazil. Retrieved: http://www.atlasbrasil.org.br/2013/pt/consulta/

Azam, S. (2017). A cross-country empirical test of cognitive abilities and innovation nexus. International Journal of Educational Development 53: 128-136.

Beraldo, S. (2010). Do differences in IQ predict Italian north-south differences in income? A methodological critique to Lynn. Intelligence 38: 456-461. 
Berr, C., Richard, M.J., Roussel, A.M., Bonithon-Kopp, C. \& EVA Study Group. (1998). Systemic oxidative stress and cognitive performance in the population-based EVA study. Free Radical Biology and Medicine 24: 1202-1208.

Bongaarts, J. (2008). Fertility transition in developing countries: Progress or stagnation. Studies in Family Planning, 39, 105-110.

Bureau of Economic Analysis, U.S. Dept. of Commerce (2016). State Personal Income 2015. News Release BEA 160-15, March 24.

Cervellati, C., Romani, A., Seripa, D., Cremonini, E., Bosi, C., Magon, S., ... \& Zuliani, G. (2014). Systemic oxidative stress and conversion to dementia of elderly patients with mild cognitive impairment. BioMed Research International 2014: 309507.

Cornoldi, C., Giofré, D. \& Martini, A. (2013). Problems in deriving Italian differences in intelligence from 2009 PISA data. Intelligence 41: 25-33.

Cornoldi, C., Belacchi, C., Giofré, D., Martini, A. \& Tressoldi, P. (2010). The mean southern Italian children IQ is not particularly low: A reply to R. Lynn (2010). Intelligence 38: 462-470.

D'Amico, A., Cardaci, M., Di Nuovo, S. \& Naglieri, J.A. (2012). Differences in achievement not Intelligence in the north and south of Italy: Comments on Lynn (2010a, 2010b). Learning and Individual Differences 22: 128-132.

Daniele, V. (2015). Two Italies? Genes, intelligence and the Italian north-south economic divide. Intelligence 49: 44-56.

Daniele, V. \& Malanima, P. (2011). Are people in the South less intelligent than in the North? IQ and the north-south disparity in Italy. Journal of Socio-Economics 40: 844-852.

Daniele, V. \& Malanima, P. (2014). Falling disparities and persisting dualism: Regional development and industrialization in Italy, 1891-2001. Economic History Research 10: 165-176.

Daniele, V., \& Ostuni, N. (2013). The burden of disease and the IQ of nations. Learning and Individual Differences, 28, 109, 118.

DeYoung, C.G., Quilty, L.C. \& Peterson, J.B. (2007). Between facets and domains: 10 aspects of the Big Five. Journal of Personality and Social Psychology 93: 880-896.

Engelsen, O., Brustad, M., Aksnes, L. \& Lund, E. (2005). Daily duration of vitamin D synthesis in human skin with relation to latitude, total ozone, altitude, ground cover, aerosols and cloud thickness. Photochemistry and Photobiology 81: 1287-1290.

Eppig, C., Fincher, C. L., \&Thornhill, R. (2011). Parasite prevalence and the distribution of intelligence among the states of the USA. Intelligence, 39, 155-160.

Eurostat (2016). Your key to European statistics. Retrieved from http://ec.europa.eu/eurostat/web/regions/data/database.

Figueredo, A.J., Cabeza de Baca, T., Fernandes, H.B.F., Black, C.J., Peñaherrera Aguirre, M., Hertler, S., García, R.A., Meisenberg, G. \& Woodley of Menie, M.A. (2017). Sequential canonical 
cascade model of social biogeography: Plants, parasites, and people. Evolutionary Psychological Science 3(1): 40-61.

Finer, L.B. \& Kost, K. (2011). Unintended pregnancy rates at the state level. Perspectives on Sexual and Reproductive Health 43: 78-87.

Fuerst, J. \& Kirkegaard, E.O. (2016a). Admixture in the Americas: Regional and national differences. Mankind Quarterly 56: 255-373.

Fuerst, J. \& Kirkegaard, E.O. (2016b). The genealogy of differences in the Americas. Mankind Quarterly 56: 425-481.

Fukuda, S., Nojima, J., Motoki, Y., Yamaguti, K., Nakatomi, Y., Okawa, N., ... \& Kuratsune, H. (2016). A potential biomarker for fatigue: Oxidative stress and anti-oxidative activity. Biological Psychology 118: 88-93.

INVALSI (2013). OCSE PISA 2012. Rapporto nazionale. A cura di INVALSI. Retrieved from http://www.invalsi.it/invalsi/ri/pisa2012.php?page=pisa2012_it_00.

INVALSI (2016). Statistiche sugli apprendimenti 2016. Retrieved from htpps://invalsiserviziostatistico.cineca.it.

ISTAT (2010). Temperature. Retrieved from http://www.istat.it/it/archivio/temperature.

ISTAT (2013). Regional economic accounts. Retrieved from https://www.istat.it/en/archive/105458.

Jablonski, N.G. (2004). The evolution of human skin and skin color. Annual Review of Anthropology, 33, 585-623.

Jablonski, N.G. \& Chaplin, G. (2010). Human skin pigmentation as an adaptation to UV radiation. Proceedings of the National Academy of Sciences USA 107: 8962-8968.

Jones, G., Strungnell, S.A. \& DeLucca, H.F. (1998). Current understanding of the molecular actions of vitamin D. Physiology Review 78: 1193-1231.

Kennedy, G., Spence, V.A., McLaren, M., Hill, A., Underwood, C. \& Belch, J.J.F. (2005). Oxidative stress levels are raised in chronic fatigue syndrome and are associated with clinical symptoms. Free Radical Biology and Medicine 39: 584-589.

Kristenasen, P., \& Bjerkedal, T. (2007). Explaining the relation between birth order and intelligence. Science, 316, 1717.

León, F.R. (2018). Diminished UV radiation enhances national cognitive ability, wealth, and institutions through health and education. Personality and Individual Differences, 120, 52-57.

León, F.R. \& Avilés, E. (2016). How altitude above sea level affects intelligence. Intelligence 58: 3341.

León, F.R. \& Burga León, A. (2014). Why complex cognitive ability increaes with absolute latitude. Intelligence, 46, 291-299.

León, F.R. \& Burga-León, A. (2015). How geography influences complex cognitive ability. Intelligence 50: 221-227. 
León, F.R. \& Burga-León, A. (2017). UV radiation associates with USA state income through complex cognitive ability. Journal of Individual Differences (forthcoming).

León, F.R. \& Hassall, C. (2017). UV radiation is associated with latitudinal trends in cognitive ability of White children in the USA. Journal of Individual Differences 38: 155-162.

Lynn, R. (2010). In Italy, north-south differences in IQ predict differences in income, education, infant mortality, stature, and literacy. Intelligence 38: 93-100.

Lynn, R. (2012a). IQs in Italy are higher in the north: A reply to Felice and Giugliano. Intelligence 40: 255-259.

Lynn, R., Antonelli-Ponti, M., Mazzei, R., Silva, J. \& Meisenberg, G. (2017). Differences in intelligence and socio-economic outcomes across the twenty- seven states of Brazil. Mankind Quarterly 57: 519-541.

Lynn, R. \& Vanhanen, T. (2012). National IQs: A review of their educational, cognitive, economic, political, demographic, sociological, epidemiological, geographic and climatic correlates. Intelligence, 40, 226-234.

Meng, J.Y., Zhang, C.Y., Zhu, F., Wang, X.P. \& Lei, C.L. (2009). Ultraviolet light-induced oxidative stress: effects on antioxidant response of Helicoverpa armigera adults. Journal of Insect Physiology 55: 588-592.

National Center for Education Statistics/Institute of Education Sciences (2016). NAEP State Comparisons. Retrieved from https://nces.ed.gov/nationsreportcard/statecomparisons.

National Weather Service (2016). UV Index: Annual Time Series. Retrieved from www.cpc.ncep.noaa.gov/products/stratosphere/uv_index/uv_annual.shtml.

National Weather Service (2017). State Annual and Seasonal Time Series, National Climatic Data Center. Retrieved from www.ncdc.noaa.gov/temp-anmd-precip/state-temps/.

Open Peer Commentary (2007). Discussion on The g-factor of international cognitive ability comparisons by Heiner Rindermann. European Journal of Personality 21: 707-765.

Organization for Economic Cooperation and Development - OECD (2016). Available at: https://www.oecd.org/pisa/pisaproducts/.

Petrarca, S., Cogliani, E. \& Spinelli, F. (2000). La radiozione solare globale al suolo in Italia. Roma: Ente per le Nuove Tecnologie, l'Energia e l'Ambiente.

Piffer, D. \& Lynn, R. (2014). New evidence for differences in fluid intelligence between north and south Italy and against school resources as an explanation for the north- south IQ differential. Intelligence 46: 246-249.

Rindermann, H. (2007a). The g-factor of international cognitive ability comparisons: The homogeneity of results in PISA, TIMSS, PIRLS and IQ tests across nations. European Journal of Personality 21: 667-706.

Rindermann, H. (2007b). The big g-factor of national cognitive ability. European Journal of Personality 21: 767-778. 
Rindermann, H., Kodila-Tedika, O. \& Christainsen, G. (2015). Cognitive capital, good governance, and the wealth of nations. Intelligence 51: 98-108.

Robinson, D., Saggino, A. \& Tommasi, M. (2011). The case against Lynn's doctrine that population IQ determines level of socioeconomic development and public health status. Journal of Public Mental Health 10: 178-189.

Rodrigues de Moura, R., Coelho, A.V.C., de Queiroz Balbino, V., Crovella, S. \& Brandao, L.A.C. (2015). Meta-analysis of Brazilian genetic admixture and comparison with other Latin America countries. American Journal of Human Biology 27: 674-680.

Schalka, S., Steiner, D., Ravelli, F.N., Steiner, T., Terena, A.C., Marçon, C.R., ... \& Duarte, I. (2014). Brazilian consensus on photoprotection. Anais brasileiros de dermatologia 89(6): 1-74. https://dx.doi.org/10.1590/abd1806-4841.20143971

Steinberg, L., Dornbusch, S. M., Brown, B. B., Stevenson, H. W., Chen, C., Stigler, J. W., \& Hsu, C. (2004). Culture and intelligence. Psychology, 18, 750-759.

Templer, D.I. (2012). Biological correlates of northern-southern Italy differences in IQ. Intelligence 40: 511-517.

U.S. Census Bureau (2011). Introduction to Census 2010 data products. Washington DC: Author, June.

U.S. Census Bureau (2016). 2011-2015 American Community Survey. 5 year estimates, educational Attainment. Retrieved from https://factfinder.census.gov/faces/tableservices/jsf/pages/productview.xhtml?src=bkmk.

U.S. Department of Labor. Bureau of Labor Statistics. (2016). State unemployment rates 2010. Retrieved from https://www.bls.gov/opub/ted/2011/ted_20110301/_data.htm.

Wang, N., Han, B., Li, Q., Chen, Y., Chen, Y., Xia, F., ... \& Lu, Y. (2015). Vitamin D is associated with testosterone and hypogonadism in Chinese men: Results from a cross-sectional SPECT-China study. Reproductive Biology and Endocrinology 13(1): 74. 